\title{
The psychoeducation needs of parents who have an adult son or daughter with a mental illness Joanne Reid ${ }^{1}$, Chris Lloyd ${ }^{1}$ and Lyn de Groot $^{2}$
}

\author{
1. Division of Occupational Therapy, School of Health and Rehabilitation Sciences, \\ University of Queensland, Australia \\ 2. Integrated Mental Health Service, Gold Coast Health District, Southport, Queensland \\ and Department of Psychiatry, University of Queensland, Australia
}

\begin{abstract}
Since deinstitutionalisation, parents of adults with mental disorders are increasingly utilised as a resource for their relatives' care. This study used a general phenomenological perspective to capture people's experiences. Semi-structured in-depth interviews were conducted with eight parents who were members of the Schizophrenia Fellowship of Southern Queensland to explore their perceptions of their psychoeducation needs. The themes that emerged included the usefulness of past experiences with psychoeducation, educational needs, barriers to accessing information and support, and other unmet carer needs, including the need for managing stress and emotional needs, recognition and inclusion of family members in decision-making, and negotiating the best care for their family member within the health care system. This study adds to an increasing body of knowledge that advocates for the greater inclusion and involvement of families in the care and treatment of their relatives. Further research into the needs of families, in particular barriers and supports in accessing information and services, is recommended.
\end{abstract}

Keywords

carers, psychoeducation, mental illness, supports, barriers

\section{Introduction}

Since deinstitutionalization, parents of adults with a mental illness have become a primary resource in their relatives' care, often responsible for providing housing, financial assistance, emotional support, case management, and advocacy for their son or daughter (Parker, 1993; Solomon, Draine, Mannion \& Meisel, 1998). Families, therefore, need information, support, education, and skills training to cope and reduce their burden (Solomon et al., 1998). Clarifying carers' needs for education and support has shown to not only increase carer satisfaction but improves perceptions of mental health professionals and participation in family treatments (Ascher-Svanum, Lafuze, Barrickman et al., 1997).

Family psychoeducation developed to further complement and improve compliance with other treatments (Goldstein, 1995). Most family psychoeducation interventions aim to enhance knowledge by providing educational material about the aetiology, diagnosis, symptoms, and course of mental illness, as well as the treatment options, and resources available for housing and rehabilitation (de Groot, Lloyd \& King, 2003). Family psychoeducation aims to address social isolation and stigma. This is achieved by directly increasing the size and complexity of the social network, by exposing the family to other

Contact: $\quad$ Dr. Chris Lloyd, Division of Occupational Therapy, University of Queensland, St Lucia, Brisbane, Queensland 4072 c.lloyd@shrs.uq.edu.au

Citation: $\quad$ Reid, J., Lloyd, C. \& de Groot, L. (2005). The psychoeducation needs of parents who have an adult son or daughter with a mental illness. Australian e-Journal for the Advancement of Mental Health 4(2) www.auseinet.com/journal/vol4iss2/reid.pdf

Published by: Australian Network for Promotion, Prevention and Early Intervention for Mental Health (Auseinet) www.auseinet.com/journal Received 24 October 2004; Revised 16 September 2005; Accepted 16 September 2005 
families like themselves, by offering a forum for mutual aid, and by giving family members an opportunity to hear the experiences of other adults who have had similar experiences and found workable solutions (McFarlane, 1994). Programmes can provide therapeutic techniques to enhance coping, problem solving, communication, and crisis intervention skills (Gasque-Carter \& Curlee, 1999; Goldstein, 1995; Goldstein \& Miklowitz, 1995; Solomon, 1996; Winefield \& Harvey, 1994). By better understanding the relevance of these programmes to the needs of family carers, future interventions may not only be more useful but effective.

Family interventions have been recommended for the treatment of schizophrenia (Lehman \& Steinwachs, 1998). The literature has shown that these interventions can lead to improvements in relapse rate and outcomes, reduction of families' expressed emotion, and enhancement of the problem-solving capacity of families (Bustillo, Lauriello, Horan \& Keith, 2001; Dixon, McFarlane, Lefley, Lucksted et al., 2001; Penn \& Mueser, 1996; Thornicroft \& Susser, 2001). Family psychoeducation has important benefits for parental carers of consumers with schizophrenia including enhanced coping skills, adaptive capacities and satisfaction, and has shown to meet some of the educational and support needs of families (Barrowclough \& Tarrier 1992; Biegel, Robinson \& Kennedy, 2000; Dixon, Adams \& Lucksted, 2000). As discussed by Dixon et al. (2001) and Solomon (1996), family psychoeducation can vary in a number of ways including the content of the information and the manner in which it is presented.

Previous studies have highlighted that valuing the subjective experiences and needs of parental carers cultivates a mutual appreciation and understanding when targeting interventions (Doornbos, 2002; Mohr \& Regan-Kubinski, 2001; Saunders \& Byrne, 2002; Tweedell, Forchuk, Jewell \& Steinnagel, 2004). Therefore, this study aims to explore the personal experiences of families with psychoeducation programmes and other education on admission and in the long term as well as establishing what parental needs and barriers exist. The following research questions guided the study:
1. What role do family psychoeducation interventions play in meeting the educational and support needs of parents?

2. What other types of information and support are needed?

3. What barriers limit carer access to meaningful and useful information? and

4. What other unmet needs do parents feel are not addressed?

\section{Method}

The study design is based on a phenomenological approach, which emphasises the direct study of personal experience (Polgar \& Thomas, 2000). In-depth interviewing was used to uncover the meaning of a lived experience by exploring participant responses to questioning (Seidman, 1991). The study asked for reflection on and discussion of issues relating to parents' psychoeducational and family care giving needs and explored the personal experiences of families. The study met the ethical requirements of the University of Queensland and was supported by the Schizophrenia Fellowship of South Queensland (SFSQ).

\section{Participants}

Eight participants were recruited for the study. All were providing a major carer role to their son or daughter. The participants' adult offspring had been diagnosed with schizophrenia, bipolar affective disorder or schizoaffective disorder. Several parents had more than one son/daughter with a major mental illness diagnosis. Seven of the eight participants were female and all were aged between 54 and 80. All participants resided along Queensland's Gold Coast. The living arrangements of participants varied and appeared to fluctuate. Several participants did not live with their son/daughter, but visited them regularly at their homes or at inpatient treatment facilities, while other participants lived with their son or daughter. The sons/daughters of the participants were aged between 21 and 52 years. Seven were male and two were female.

\section{Procedure}

The selection of participants was purposive, as participants were deliberately approached with the help of a local carer support agency, the SFSQ. The researcher attended the SFSQ's carer support meetings, gave a description of the study 
and information sheet outlining the purpose and nature of the research. Carers were advised that they were under no obligation to participate in the study. Interview questions were formulated from the literature and through brainstorming with colleagues.

As one of the major aims of the study was to uncover the subjective experiences of the participants, data was collected through semistructured in-depth interviews (see Appendix 1 for an outline of the interview schedule). For convenience, interviews were conducted at community locations before and after SFSQ carer meetings. Informed consent was obtained prior to conducting the interviews. Each participant was interviewed alone, unless they wished a spouse or family member to be present. Interviews were transcribed from audiotaped recordings. The computer programme NVivo (Qualitative Solutions and Research, 1999) was used to form a conceptual model of the links between the themes and concepts that emerged.

Rigour was ensured by the use of cross-check questions, participant checks, peer checks, and reflective journaling (Krefting, 1991). Throughout the interview, the researcher used paraphrasing and cross-check questions to ensure that the correct conclusions were made, without bias or distortion. Participants were sent a transcript of the interview and the encoded themes to clarify any conclusions, ensure the validity of the findings, and highlight any bias. The researcher also kept a journal of data collection and analysis experiences, which was used to judge the bias and limitations of the study. An independent colleague coded the data, which was then compared with the researcher's coding scheme. Areas of agreement and disagreement were identified and discussed and categories were amended where appropriate.

\section{Findings}

The major themes that emerged from the interviews with the parents were experiences with psychoeducation, information and educational needs, barriers to accessing information and support, and other unmet needs.

\section{Psychoeducation experiences}

Participants discussed the usefulness of family psychoeducation, the inclusion of their son or daughter, flexibility and choice of programme, duration and frequency, and the location of the programmes as the most pressing issues.

Usefulness of psychoeducation. Participants showed mixed feelings about the usefulness of psychoeducation programmes in which they had participated. Some felt that psychoeducation programmes could not offer many new insights. 'I doubt that anybody doing those programmes would know as much as I know' (Participant 1). Others had found areas such as communication and coping skills were very useful. 'Things like, the way you spoke, like I've heard it many times before, but when you, when it actually comes up, you know you should be using those skills' (Participant 8).

Inclusion of family members. Participants shared ambivalence about whether or not the adult son or daughter with a mental illness should be included in the programme. They felt that their son or daughter may not recognise the importance of involvement due to a lack of insight into their illness. 'They'll say, I haven't got that, there's nothing wrong with me', but that a chance to discuss issues with their son and daughter might be useful. 'It's good to talk in front of them, in my opinion, and say well this is what I see, even if you don't. You're entitled to say what you need to say' (Participant 7).

Programme flexibility. Each of the participants was able to clearly articulate the format of educational programmes that would best suit their needs. Offering flexible programmes with alternate sessions was highly recommended by several participants. 'I think they should be given at centrally located places and probably a variety of times, so perhaps they could run one course in the daytime and then an alternate one in the evening to accommodate everybody' (Participant 2). When it came to attending programmes, another participant agreed that whilst they'd 'probably work around it if it really looked good' they would 'probably be more inclined to go to something that was at a time that was suitable' (Participant 8).

Home-based programmes. Participants dismissed the notion of holding psychoeducation programmes at a person's home. Most participants thought that home-based programmes would be inconvenient and 
negatively affect other family members, including their son or daughter with the mental illness.

If (my son) was home that would not be convenient, because part of the illness is that they don't like strangers and they don't trust strangers... they're not comfortable with people coming into the house... and ...I have a daughter who may not want to be involved and that would inconvenience her. (Participant 3)

Several participants also felt that home-based programmes would be unfair on the host.

I think you live under so much stress... but you like to go round and tizzy up a bit more if people are coming in to your home. So I think it's better somewhere outside. (Participant 5)

\section{Barriers and supports}

As well as psychoeducation programmes, participants reported receiving information and support from many services and resources including health professionals, books, pamphlets, support groups, conferences, lectures, and the Internet to assist them with their carer role. Throughout this process participants identified a number of barriers and supports, which limited or encouraged their participation in programmes or access to information and services.

Barriers to information. Psychoeducation programmes that were held at night were not considered as convenient or accessible as ones held during the day. Due to difficulties of access to transport, fatigue and driving concerns, most participants agreed that night programmes would best be held at other times. Older participants found this of particular concern.

At our age now, we don't like going out of a night time very much. Because we have eyesight problems and all that sort of thing, and you want to stay home because you get exhausted. (Participant 5)

Furthermore, participants identified access to programmes both for those who drive, 'it's a little bit far for me to travel at night... I've got a car, but its very dark, the road, you know, at night' (Participant 6) and those who caught public transport 'if they're at night I won't go out on buses' (Participant 7). Another barrier to carer participation in educational programmes was the restriction felt due to the responsibility of caring for their son or daughter.

You can't always just say, 'Oh, well I'll get up and go'. Like today, he was going for this interview, and I nearly went with him because, I thought he won't be able to find where he was going. But I was lucky that someone else rang up and said that they would take him, so that let me come to the meeting, otherwise I wouldn't have been here. (Participant 7)

Attitudes of health professionals. Doctors' and other health professionals' lack of empathy and understanding of carers' needs was raised consistently throughout the interviews as one of the largest barriers to accessing information and support. One participant believed that she received no understanding from clinicians throughout her experiences as a carer, 'I found them very cold...you don't really get much empathy at all' (Participant 6). Another participant reported a similar situation.

Well, I think with the health professionals, they become general public servants, we get the opinion they'll... that it's just a 9 to 5 job and then they go home. (Participant 5)

Parents spoke of the frustrations they experienced, particularly when they felt their intentions for their family member were being questioned 'they must know we're sincere and that we love our children to death' (Participant 6). Overwhelmingly, participants believed that 'everyone can do with more support when they've got anyone with any illness' (Participant 7). Some participants believed that when they did feel empathy from staff, they found it gave them 'the will to carry on' (Participant 6).

Participants also highlighted that health professionals' expectations of their level of understanding was another barrier parents faced when accessing information about their son or daughter's illness and treatment. On admission, parents felt that more specific information from health professionals would have been useful. Several participants felt that health professionals 'expect that you know what's going on' and therefore for many parents, information 'wasn't offered at all' (Participant 2). Often the only information given to participants was from a brief discussion with a doctor or health professional. Participants spoke of the explanations and advice they had received on 
symptoms, diagnosis, services, and coping strategies, with mixed opinions.

Whilst participants were able to identify some specific questions during the care for their son or daughter, many believed that they 'didn't even know what questions to ask' (Participant 4). Many parents felt they needed more information about what to expect with treatments, especially when it came to medication and side effects. Most parents agreed that at some time throughout their family member's illness they 'didn't have a clue what to do' and were 'just sort of walking in a blind state... sort of feeling my way' (Participant 3). Parents agreed this was compounded by the fact they 'definitely didn't feel that we got enough information' (Participant 4).

Processing information. Another barrier explored was whether families were ready and able to absorb information on admission. Participants had mixed impressions about the role of written information in overcoming this obstacle. One participant felt that 'you get a lot of information in writing...but you don't always take all that in' (Participant 7). Another participant found that written information had seemed to have 'gone in one ear and out the other' (Participant 4). One participant concluded that because the information given cannot always be absorbed all at once, written information that can be regularly revisited was important and that pamphlets 'are an important part of the learning process... because you cannot possibly absorb everything' (Participant 1).

Many believed that admission was not always the ideal time to receive information, 'I was too emotional, I think' (Participant 7) and found that when given an opportunity to ask questions at this time it was not utilised, "it was like a shock so I had really no questions to ask, like I was blank' (Participant 2). Many participants found the situation was 'just all very floundering' (Participant 4) and that for a long time they 'were just in such shock' (Participant 2). Participants concluded that there was a time that they started to need information to cope, but this time varied for each person.

Searching for information. Many parents appeared to compensate for their lack of access to information by becoming more assertive and proactive in their search for information and resources. 'I don't think I was offered much information from the hospital and I decided well I'm just going to have to learn about it for myself' (Participant 4). They described the experience of having to 'search things out' (Participant 2). Even parents with many years of experience with mental illness found that there were 'still learning' (Participant 5) to 'initiate', be 'more vocal' and 'stand up for myself' (Participants 1 and 4).

Parents also saw the need for vigilance when it came to pursuing continual education and advocacy skills to increase their participation in their son or daughters' recovery. One participant felt that unless consistent access to information and established services is maintained, it is difficult to manage care at times of crisis.

I have noticed that when your child is well, you are well and when you're child is unwell, you are unwell...you're coping with all the changes and information and therefore it's hard to get a lot of services into action if you don't have that continuity of assistance. (Participant 2)

Several participants felt that in hindsight some situations may have been easier if they had been kept better informed throughout their son or daughters' care. Ultimately, participants agreed that maintaining contact with services and keeping informed is an important way to manage the carer role.

I think you need to be vigilant, whether our child is well or not, to keep them going, to add more information, to support them, to build them up so they get more support, more government support. (Participant 3)

Several participants highlighted the need for contact with other families through educational programmes or support groups. Participants identified that talking with parents in similar carer roles was positive because it gave them perspective. One participant stated that even though she had 'been through hell', hearing someone else's story made her realise 'it's not as bad' (Participant 5). Participants agreed that contact with others helped reduce isolation. 'I think it makes you feel a lot better... when you meet others, you know that you're not on your own. But otherwise you're there thinking, I'm the only one that's got this' (Participant 5). 
Participants believed that other carers and families provide an important support network. 'You know you all have your ups and downs and you're all there to give that support' (Participant 7). Other participants even found it an important social contact to 'have a night out' (Participant 3) or 'have lunch' (Participant 6).

\section{Other unmet carer needs}

Throughout the interviews it was evident that parents were identifying a range of needs (other than for more information or education) that were seemingly unmet, which limited their satisfaction and affected the care of their son or daughter. These unmet needs included managing stress and emotional needs, recognising and including family members in care, and negotiating the best care for their family member within the health system.

Stress and emotional needs. Participants discussed their experiences with dealing with stress, grief and feelings of hopelessness, and the need to manage these emotions for good health. One participant did not know why many parents 'don't end up having a breakdown' (Participant 6), especially after being told by her own GP that he couldn't 'do anything until your son gets well' (Participant 6). Participants readily spoke of their feelings of grief and one parent felt that she was grieving for her son because he 'wasn't the person that was there before and you're grieving for someone that has died' (Participant 5). It was evident that participants experienced intermittent feelings of hopelessness but that they had an ultimate commitment to the ongoing carer role.

Sometimes you feel you can't deal with it anymore, I love (my son) so much and I've decided that above all I feel we'll be here for him, I feel I've had my life... I could never ever walk away. (Participant 6)

Recognising and including family members. The need for recognition and greater involvement was identified by families in almost every aspect of care for their son or daughter. Parents expressed their frustration at the lack of involvement and acknowledgment they received as carers. One participant felt that during treatment 'we should be having a family discussion about it' (Participant 1). Others agreed with the usefulness of including family members in treatment, however 'it was never offered and it didn't seem something that was too easy to arrange' (Participant 2).

Whilst the need for recognition and involvement was sometimes unmet, there were occasions where families felt they were being consulted on the treatment and planning.

They've been really good talking to us... I used to go to the Doctor's with him... that's never a problem, as long as (my son) lets me go, they've always let me go in with him. (Participant 4)

One participant highlighted that 'the best thing I think was being kept informed... even if they say, we can't divulge anything, it's still contact, it's still saying well you are the mum' (Participant 8). On occasion, participants outlined experiences where involvement and collaboration with health professionals was encouraged. Equally, participants had experiences where there was little to no inclusion of parents in treatment.

Several participants believed that, on occasion, not being involved in their son or daughter's treatment suited their situation at the time as they had 'been through enough trauma' (Participant 6). There was general agreement that there should not only be greater choice as to whether parents are involved in the treatment of their son or daughter, but that opportunities for input are given in appropriate situations.

Many parents found that because their son or daughter was recognised as 'an adult' who was 'over the age' treatment teams did not have to include family in treatment or decision making processes (Participant 3). Often parents felt this was inadequate as their sons and daughters were often 'too sick to get the information' necessary for their best interest. Most participants agreed that in this situation, they, as carers should have been given the information on their son or daughter's behalf as health professionals are 'not only dealing with their patients, they're dealing with the parents or the person who is caring for them' (Participant 6).

\section{Frustration with the system}

Participants faced deep frustration when negotiating services and treatments within the mental health system, particularly when describing a need for greater continuity of 
services their son or daughter received. Many felt this was important for the quality of care and support received. 'There isn't the continuity of the doctor; there isn't the continuity of the service, there isn't the continuity of therapy, which I think is a valuable part' (Participant 2). For the majority of participants, inefficient collaboration between services became a source of frustration 'I just felt there was no correlation between anything... that was a really big hole... but that was a big problem' (Participant 8).

Participants felt that the adequate care and treatment of their family member was seriously compromised by both staff and hospital bed shortages. Parents felt that often treatment plans were 'not followed through by the staff' perhaps due to lack of time or because there was 'not enough staff to get to it quick enough' (Participant 2). Parents stated they believed that services 'understaffed' and staff 'underpaid', however found that 'as parents, you can only consider one thing, what's best for your child' (Participant 2). Another participant stated that she understood the pressures on health services and staff, 'I feel for them because I feel that they've got too many pressures and not enough staff' (Participant 5).

Almost all participants had experienced a lack of hospital beds for their loved ones in times of need. 'We thought we'd have to put him in to hospital he was so bad, but I knew there was no hospital beds' (Participant 5). One participant told of the regular experience of "waiting all night long for him to get admitted only to be told he's ok or there's no beds' (Participant 8).

Participants explained their frustration with the processes for accessing the mental health system, particularly when their son or daughter required involuntary treatment. 'With a mental illness, it's very hard for you to say... they need treatment, without them having to go through this long process' (Participant 7). Participants described negotiating between the hospital, police and courts 'It was a really difficult procedure... just negotiating the system' (Participant 8).

\section{Advocacy}

Participants showed continued concern about the influence of community attitudes on their ability to discuss mental illness openly and identify a problem and access services. One participant found that her granddaughter was unable to communicate with other students at her school about her mother's illness due to the surrounding stigma. 'From ten to her age now, she hasn't been able to talk to her peers because of the sickness' (Participant 1).

Others felt that whilst they were fearful about discussing mental illness with someone else, opening up about it was easier than anticipated.

You go to work and you start talking about things and it's just all too scary...but I've been really open about it... It's quite amazing now when I start talking about it and they say 'Oh yeah, I know somebody'. (Participant 4)

It was widely stated that the experience of carers and their families would have been made easier if governments 'would educate the general public about mental illness'. One participant felt that better awareness would prepare families for the possibility of mental illness and lead to earlier detection and treatment.

We ignored it more than what we should have done and we should have got him help sooner than what we did. So we need greater community education'. (Participant 5)

\section{Discussion}

This study sought to understand the education needs of parents who have an adult son or daughter with a mental illness. The participants in this research spoke of needs concerning the admission phase, psychoeducation programmes and ongoing education and information. Furthermore, participants spoke about their feelings as well as other ongoing unmet needs. It would appear that consideration of some of these unmet needs could be incorporated into a psychoeducation programme.

Information needs at the admission phase appear to be the most problematic. Participants in this study wished for more specific information about the illness and what to expect from mental health services. Previous research has shown that carers are dissatisfied with the amount of knowledge they have and want more information about their family members' illness and available treatments (Hodgson, King \& Leggatt, 2002; Gasque-Carter \& Curlee, 1999; Scharer, 2002; Winefield \& Harvey, 1994). Participants expressed concern that they were often not 
included in the management plans for their person with the mental illness. This is despite the National Mental Health Plan 2003-2008, which states that mental health services should become more responsive to the needs of carers and that their role must be recognised and supported (Australian Health Ministers, 2003). Noble and Douglas (2004) found that among other things, parents want more information, greater involvement in decision-making, and clearer management plans. It would be impractical to run a full psychoeducation programme for each new admission, and, as the parents indicated, they are so overwhelmed with emotion that they would have difficulty understanding a large amount of material. On first presentations to hospital, parents indicated they don't even know where to begin to ask questions.

There may be strategies that could be implemented at the admission phase to help address parents' concerns. Firstly, it may help to have an appointed person in each ward or hospital whose job is to meet with parents to explain personnel and procedures, and basic information on mental illness and medication. This person might then be available by phone or in person for further questions as they arise. In difficult situations, the person may also need to act as an advocate (as identified by GasqueCarter \& Curlee, 1999). The appointed person might be a staff member, an employed consumer or carer consultant, or a volunteer, perhaps from a non-government organisation.

Despite some participants in this study finding written information unhelpful, others found they were able to refer to it when they were ready. It may also allow clarification or memory prompts at a later date. For these reasons, it may be efficacious to provide written material to parents while their son or daughter is in hospital. It would also appear that ongoing education, and reminders to staff of the parents' need for consideration and collaboration, would go a long way to alleviate problems encountered by parents.

This study confirmed previous research that found carers perceived a lack of communication and involvement in the treatment and planning with their son or daughter (Hodgson et al., 2002). Solomon et al. (1998) reported that clinicians frequently lack an awareness of families' needs for information and this meant that families who do not express their needs effectively find them unmet. A number of studies have highlighted the importance of collaborative roles for families and mental health professionals (Doornbos, 2002; Peternelj-Taylor \& Hartley, 1993; Saunders \& Byrne, 2002; Tweedell et al 2004). It is important that professionals recognise the strengths of families and the tremendous burden that they cope with on a daily basis. Families with a collaborative relationship with professionals suffer less stress (Greenberg, Greenley \& Brown, 1997). The work of Milliken and Northcott (2003), which parallels the parental experience of not being consulted or being silenced by professionals, with the plight of other oppressed and marginalised community groups needs to be pointed out to professional caregivers. The work of Mohr and Regan-Kurbinski (2001) also needs to be emphasised to professionals, which posits that families dealing with mental illness need as much empathy and understanding, as families with a long term illness such as cancer. The ongoing education and awareness enhancement of staff would require support at the highest level of management and policy.

The awareness of carers' needs should not be limited to hospital staff as the lack of collaboration was also experienced when the care was transferred to community health services. To further assist parents to gain the inclusion they seek, teaching assertiveness skills in communicating their needs to health professionals could be included in a psychoeducation programme. Participants had several other suggestions on how psychoeducation programmes could better suit their needs. Having an impartial trained facilitator was seen as being important to ensure that the programme was relevant to all members. It has been reported that some models of family psychoeducation can be hindered by lack of programmatic leadership (Dixon et al., 2001). De Groot et al. (2003) suggested that the lack of training of facilitators and variability in programme content resulted in a limited impact on clinical outcomes and experience of caregiving.

The issue of having the adult offspring attend the programme was discussed but on the whole the 
participants did not see that their offspring should be attending. When the son or daughter is not included, it gives family members the opportunity to freely discuss issues of primary concern to them (Solomon, 1996). PeterneljTaylor and Hartley (1993) stressed that an important aspect of family psychoeducation was assisting families to sort out the feelings caused by the family member's illness.

The participants established that flexibility and choice is important for the success of family psychoeducation programmes. Doornbos' (2002) recommendations for the construction of a roster of topics or services for formal psychoeducation programmes that would enable families to choose participation based on their perception of their needs, together with Solomon's (1996) reported success of open-ended programmes with attendance frequency and duration determined by a family based on their perceived needs, would appear to be a particularly useful model.

In practice this may mean that initially a list of topics would be scheduled, perhaps once weekly over two months, but in the long term other topics could be added as suggested by parents. Over a year or more parents could attend sessions they had missed because of other commitments or lack of relevance to their situation at the time (e.g. dealing with depression or burnout). This model supports the literature that emphasises the importance of ongoing guidance, emotional support and education for families, regardless of the length of time their family member had been ill and particularly during their son or daughter's treatment (Dixon et al., 2000; Greenberg, Greenley \& Kim, 1995; Tweedell et al., 2004)

Some studies have shown that home-based programmes are more accessible for some families, particularly low-income groups (Solomon, 1996). The participants in this study did not like the idea of home-based programmes as they felt that it would be an imposition on the person hosting the session. Similar to research by Ascher-Svanum et al. (1997) and GasqueCarter \& Curlee (1999) participants seemed to show a preference for a non-threatening health care setting for family psychoeducation programmes. However, they were concerned about some of the difficulties in accessing programmes, most notably driving or catching public transport after dark. It has previously been reported that the barriers of transportation and distance and the responsibility of caregiving are common limitations for parents wishing to access psychoeducation programmes (Biegel \& Song, 1995; Gasque-Carter \& Curlee, 1999; Solomon, 1996).

Isolation and loneliness were common themes. Participants expressed the usefulness of family psychoeducation in being able to talk with other parents, giving them a new perspective on the situation. They also found family psychoeducation useful in reducing social isolation by increasing their social networks. Research in this area supports the idea that group family interventions help reduce isolation and loneliness felt by family members (Cazzullo, Bertrando, Clerici et al., 1989). They experience the support and validation of others in similar situations as they share experiences, feelings, problems, and difficulties (Peternelj-Taylor \& Hartley, 1993), in addition to exchanging valuable information about the practical aspects of caregiving (Chambers, Ryan \& Connor, 2001). Studies show that families do find the social support, interaction and networking with other carers as useful for providing crisis intervention, resource information, coping strategies, feedback, and empathy (Doornbos, 2002; McFarlane, 2001; Saunders \& Byrne, 2002).

Overwhelming feelings were expressed by the participants in dealing with the illness and the effect it had on their day-to-day lives. This is a similar finding to other qualitative studies of families' experiences in which overwhelming feelings were recurring themes (Chambers et al., 2001; Mohr \& Regan-Kubinski, 2001; Saunders \& Byrne, 2002). Furthermore, Mohr and ReganKubinski (2001) and Parker (1993) reported that the bereavement associated with having a family member with a mental illness is devastating as it is punctuated by remissions, which offer moments of hope that can make the loss seem ongoing and chronic. It might help to mitigate some of this pain if information on emotions often experienced by families with a son or daughter with a mental illness were incorporated into the programme, to reinforce that their feelings were shared by others. Coping skills 
could also be taught. Importantly, professionals should provide a feeling of hope that recovery is possible. Apart from providing information, Linzen, Dingeman, van der Docs et al. (1996) emphasised the importance of allowing carers the time in the group to deal with their emotions, especially the parents of people with a recent onset psychosis.

Participants spoke about the need to educate the community and reduce stigma. Czuchta and McCay (2001) support the idea that reducing stigma would help reduce the burden that caring for a son and daughter places on parents. It has been suggested that a community that is perceived as rejecting makes life even more difficult for carers, and that steps need to be taken to create more supportive and understanding communities (Struening, Perlick, Link et al., 2001). It may be beyond the scope of a psychoeducation programme to be involved in public education and activism to improve conditions in the mental health system that parents found distressing, such as long admission processes and bed shortages. However, the programme could direct parents to organisations in the community whose brief includes these things, such as the Schizophrenia Fellowship.

Many of the issues and concerns identified in our Australian study are similar to other work exploring parents' experiences of the mental health system. It is of concern that despite guidelines that support carer participation, it appears that in many instances these are not followed. The National Practice Standards for the Mental Health Workforce explicitly states that 'mental health professionals [should] engage consumers, family members and/or carers as full collaborators in treatment, service planning, development, implementation and evaluation' (Commonwealth Department of Health and Ageing, 2002:11). Furthermore, it is stated that mental health professionals should 'develop a comprehensive care plan collaboratively with the consumer and other people nominated by the consumer' (Commonwealth Department of Health and Ageing, 2002:25). This study has provided an important contribution to the literature concerning the perceived needs of carers around admission, especially first admission.

\section{Limitations and further research}

There are a number of limitations associated with this study. All participants were from one geographic area and had been involved in the same local mental health service. Participants were all members of the SFSQ support group and as such may differ in significant ways from the larger population of carers, in that they may be more proactive and have greater expectations of the mental health system. Despite these limitations, the findings of this research are presented in sufficient detail to enable readers to evaluate the relevance to their situations (Krefting, 1991).

Further research in this area is needed to better understand what parents with a son or daughter with a mental illness need, not only from psychoeducation interventions but from the health system as a whole. Whilst there is an emerging body of research on carer needs, greater investigation particularly of the subjective experiences of families, would give better insight into the positive and negative experiences of carers. Research with families shortly after they have participated in psychoeducation programmes would highlight which aspects of an intervention are most helpful at that time. Further investigation of the barriers and supports to accessing information or services could help shape future service development and delivery. Most importantly, further research needs to evaluate current or potential strategies that increase the level of carer participation in their relatives' treatment planning and service delivery.

\section{Conclusion}

This study has explored the experiences and needs of parents who are caring for a son or daughter with a severe mental illness. Whilst the initial scope of this study was to target only the psychoeducation needs of families, it became evident that parents had many other, seemingly unmet needs. The participants of this study have raised many important and widely recognised issues for parental carers of people with a mental illness.

Whilst it is evident that parents are clearly able to articulate their needs, this does not imply that parents should have to become more responsible for the care of their son or daughter. Identifying 
and addressing the needs of families should instead be about structuring services and supports so that meaningful participation by consumers and their carers can become a reality. This study adds to an increasing body of knowledge, which advocates for the greater inclusion and involvement of families in the care and treatment of their relatives. The emotive responses in this study highlighted not only the complex and sometimes distressing nature of caregiving, but also how this distress was intensified by structural barriers that prevented the fulfillment of family needs.

\section{Acknowledgements}

The parents who participated in interviews, as well as Pamela Grey and the Gold Coast Branch of the Schizophrenia Fellowship of South Queensland, are gratefully acknowledged and thanked for their contributions to this research. This article is based on a research report submitted as a partial requirement for an Honours degree in Occupational Therapy at The University of Queensland, Australia, by the first author.

\section{References}

Ascher-Svanum, H., Lafuze, J., Barrickman, P., Van Dusen, D., \& Fompa-Loy, J. (1997). Educational needs of families of mentally ill adults. Psychiatric Services, 48, 1072-1074.

Australian Health Ministers (2003). National Mental Health Plan 2003-2008. Canberra: Australian Government.

Barrowclough, C., \& Tarrier, N. (1992). Interventions with families. In: M. Birchwood and N. Tarrier (Eds.). Innovations in the Psychosocial Management of Schizophrenia (pp. 79- 101). London: John Wiley and Sons Ltd.

Biegel, D.E., Robinson, E.A.R., \& Kennedy, M.J. (2000). A review of empirical studies of interventions for families of persons with mental illness. Research in Community and Mental Health, 11, 87-130.

Biegel, D.E., \& Song, L. (1995). Facilitators and barriers to caregiver support and group participation. Journal of Case Management, 4, 164-172.

Bustillo, J., Lauriello, J., Horan, W., \& Keith, S. (2001). The psychosocial treatment of schizophrenia: An update. American Journal of Psychiatry, 158, 163-175.
Cazzullo, C., Bertrando, P., Clerici, D., Bressi, C., Da Ponte, D., \& Albertini, E. (1989). The efficacy of an information group intervention for relatives of schizophrenics. International Journal of Social Psychiatry, 35, 313-323.

Chambers, M., Ryan, A. \& Connor, S. (2001). Exploring the emotional support needs and coping strategies of family carers. Journal of Psychiatric and Mental Health Nursing, 8, 99-106.

Czuchta, D., \& McCay, E. (2001). Help-seeking for parents of individuals experiencing a first episode of schizophrenia. Archives of Psychiatric Nursing, 15, 159-170.

Commonwealth Department of Health and Ageing (2002). National Practice Standards for the Mental Health Workforce. Canberra: Commonwealth of Australia.

De Groot, L., Lloyd, C., \& King, R. (2003). An evaluation of a family psychoeducation program in community mental health. Psychiatric Rehabilitation Journal, 27, 18-23.

Dixon, L., Adams, C., \& Lucksted A. (2000). Update on family psychoeducation for schizophrenia. Schizophrenia Bulletin, 26, 5-20.

Dixon L., McFarlane W R., Lefley H., Lucksted A., Cohen M., Falloon I., Mueser K., Miklowitz D., Solomon P., \& Sondheimer D. (2001). Evidencebased practices for services to families of people with psychiatric disabilities. Psychiatric Services, 52, 903910.

Doornbos, M. (2002). Family caregivers and the mental health care system: Reality and dreams. Archives of Psychiatric Nursing, 16, 39-46.

Gasque-Carter, K., \& Curlee, M. (1999). The educational needs of families of mentally ill adults: The South Carolina experience. Psychiatric Services, $50,520-524$.

Goldstein, M. (1995). Psychoeducation and relapse prevention. International Clinical Psychopharmacology, 9, 59-69.

Goldstein, M., \& Miklowitz, D. (1995). The effectiveness of psychoeducational family therapy in the treatment of schizophrenic disorders. Journal of Marital and Family Therapy, 21, 361-376.

Greenberg J.S., Greenley J.R., \&Brown R.L. (1997). Do mental health services reduce distress in families of persons with serious mental illness? Psychiatric Rehabilitation Journal, 21(1), 40-50.

Greenberg, J.S., Greenley, J.R., \& Kim, J. (1995). The provision of mental health services to families of 
persons with serious mental illness. Research in Community and Mental Health, 8, 181-204.

Hodgson, O., King, R., \& Leggatt, M. (2002). Carers of mentally ill people in Queensland: Their perceived relationships with professional mental health service providers: Report on a survey. Australian e-Journal for the Advancement of Mental Health, 1, 1-15. http://auseinet.flinders.edu.au/journal/volliss3/hodgs on.pdf

Krefting, L. (1991). Rigor in qualitative research: The assessment of trustworthiness. American Journal of Occupational Therapy, 45, 214-222.

Lehman, A. \& Steinwachs, D. (1998). At issue: Translating research into practice: the Schizophrenia Patient Outcomes Team (PORT) treatment recommendations. Schizophrenia Bulletin, 24, 1-10.

Linzen, D., Dingemans, P., van der Docs, J., Hugter, A., Scholte, P., Lenoir, R., \& Goldstein, M. (1996). Treatment, expressed emotion, and relapse in recent onset schizophrenic disorders. Psychological Medicine, 26, 333-342.

McFarlane, W.R. (1994). Multiple-gamily groups and psychoeducation in the treatment of schizophrenia. New Directions for Mental Health Services, 62, 1322.

McFarlane, W.R. (2001). Family psychoeducational treatment. In A. Gurman \& D. Kinisken (Eds.), Handbook of Family Therapy Volume II (pp.363395). New York: Brunner/Masel.

Milliken, P., \& Northcott, H. (2003). Redefining parental identity: Caregiving and schizophrenia. Qualitative Health Research, 13, 100-113.

Mohr, W., \& Regan-Kubinski, J. (2001). Living in the fallout: Parents' experiences when their child becomes mentally ill. Archives of Psychiatric Nursing, 15, 69-77.

Noble, L.M., \& Douglas, B.C., (2004). What users and relatives want from mental health services. Current Opinion in Psychiatry. 17, 289-296.

Parker, B. (1993). Living with mental illness: The family as caregiver. Journal of Psychosocial Nursing, $31,19-21$.

Patton, M. (2002). Qualitative Evaluation and Research Methods ( $3^{\text {rd }}$ edition.). Newbury Park, CA: Sage.
Peternelj-Taylor, C., \& Hartley, V. (1993). Living with mental illness: professional/family collaboration. Journal of Psychosocial Nursing, 31, 23-28.

Penn, D., \& Mueser, K. (1996). Research update on the psychosocial treatment of schizophrenia. American Journal of psychiatry, 153, 607-617.

Polgar, S., \& Thomas, S. (2000). Introduction to Research in the health Sciences, $\left(4^{\text {th }}\right.$ edn.) Edinburgh: Churchill Livingstone.

Qualitative Solutions and Research. (1999). Nvivo Reference Guide. Melbourne, Australia: Qualitative Solutions and Research.

Saunders, J.C. \& Byrne, M.M. (2002). A thematic analysis of families living with schizophrenia. Archives of Psychiatric Nursing,. Oct, 16(5),217-23.

Scharer, K. (2002). What parents of mentally ill children need and want from mental health professionals. Issues in Mental Health Nursing 23, 617-640.

Seidman, D. (1991). Interviewing as Qualitative Research: A Guide in Education and the Social Sciences. New York: Teacher's College Press.

Solomon, P. (1996). Moving from psychoeducation to family education for families of adults with serious mental illness. Psychiatric Services, 47, 1364-1370.

Solomon, P., Draine, J., Mannion, E., \& Meisel, M. (1998). Increased contact with community mental health resources as a potential benefit of family education. Psychiatric Services, 49, 333-339.

Struening, E., Perlick, D., Link, B., Hellman, F., Herman, D., \& Sirey, J. (2001). The extent to which caregivers believe most people devalue consumers and their families. Psychiatric Services, 52, 1633 1638 .

Thornicroft, G., \& Susser, E. (2001). Evidence-based psychotherapeutic interventions in the community care of schizophrenia. British Journal of Psychiatry, $178,2-4$

Tweedell, D., Forchuk, C., Jewell, J., \& Steinnagel, L. (2004). Families' experience during recovery or nonrecovery from psychosis. Archives of Psychiatric Nursing, 17, 17-25.

Winefield, H., \& Harvey, E. (1994). Needs of family caregivers in chronic schizophrenia. Schizophrenia Bulletin, 20, 557-566. 


\section{Appendix 1. Interview Schedule}

\author{
Introduction and rapport building \\ Gender \\ Age \\ Suburb \\ Cultural background \\ Age of son/daughter \\ Date of diagnosis
}

1. Tell me about your experience with treatments for your son/daughter:

Admission

Has your child had experiences with:

- Involuntary admission

- Police involvement

- Seclusion

Were you involved in your son/daughter's admission?

What sort of questions did you want to ask at admission? Were they answered?

What sort of initial information were you offered? Could the information have been offered in a better way?

Treatment

Has your child ever received:

- Acute inpatient care?

- Counselling (for you or your son/daughter)?

- Group therapy?

Have you ever received:

- Counselling (for you or your son/daughter)?

- Group therapy?

- Family therapy?

- Psychoeducation?

When? For how long?

Where?

Was it individual or a group programme?

Did your son/daughter attend the

programme?

Did you receive information about:

Mental Health Act?

Hospital procedures and admission?

Crisis intervention and where to go for help?

Diagnosis and what it means?

Symptoms of the illness?

Medication and side effects?

Community resources?

Communication and problem-solving?

Coping skills?

\section{Discharge}

Have you or your son/daughter ever been consulted about or involved in:

- Treatment planning?

- Discharge planning?

- Goal setting?
Follow-up

Has your son/daughter ever received or attended the following?

- Case management?

- Psychiatric appointments?

- Rehabilitation referral?

2. How did you feel when your son/daughter first became ill? What sort of things would you have found helpful at that time?

3. Have you or your son/daughter ever sought assistance or information or help because you:

- Could not find it from a health service or professional

- Weren't offered it

- Were unsatisfied with the information already given

- Needed further clarification

4. At what time did you have the most questions and concerns regarding your son/daughter's well being? What time have you felt most prepared for answers or resources?

5. In what way would you find the information best presented?

- Information packs?

- Leaflets?

- Individual counselling sessions?

- Family psychoeducation?

6. If you were to attend a family psychoeducation programme, what times would suit you best to attend?

Evenings? Mornings? Afternoons?

Weekdays? Weekends?

7. How often and for how long would you find this programme useful?

Weekly? Monthly?

One session? Regular sessions for a week? Two weeks? Several months? Ongoing?

8. Where would a session best be held?

- At home?

- At a hospital?

- In the community?

9. Would you find a group session with other families useful, or would you prefer to attend sessions individually?

10. Is there anything you would prefer to have in common with other families?

- Your son/daughter's diagnosis or the times since their diagnosis?

- Ethnicity?

- Experience with health services

11. Are there any other comments you would like to add? 